\title{
Brief analysis on the innovation of logistics management in E-commerce Lei Wang
}

\author{
Zhengzhou Institute of Technology, Zhengzhou Henan, 450000,China
}

Keywords: logistics management, E-commerce, Innovative measures.

\begin{abstract}
E-commerce is a new management method in logistics management requiring management staff to apply e-commerce based on their management requirements. But currently some logistics management staff are still using e-commerce model when applying various e-commerce technologies which cannot improve the application efficiency of various e-commerce technologies. Thus, logistics management staff should formulate e-commerce innovation system and improve logistics management working quality.
\end{abstract}

\section{Introduction}

Logistics management staff must comprehensively innovate related technologies and transfer traditional logistics basic management methods and perfect related policy and regulations and improve e-commerce logistics information level and increase the working efficiency of logistics distribution so as to lay solid foundation for its subsequent development.

\section{Analysis on common issues of logistics management in e-commerce}

In e-commerce, major issues existing in logistics management include the backward management model, imperfect management policies and regulations, low informatization level, and low distribution efficiency so that it is hard to improve logistics management efficiency and it may even lead to some unsolvable issues as follows:

Firstly, logistics management in e-commerce is backward. Although the logistics management model Chinese e-commerce has progressed, due to the limitation of management concept, system and technology in logistics management, it is hard to improve its application level. Therefore, In Chinese e-commerce, logistics management is still backward, hard to satisfy the current social demand. For example, the logistics management transportation and communication facilities, warehouse equipment, information and communication equipment in e-commerce are lagged behind which make it hard to improve logistics management working efficiency.

Secondly, policies and regulations of logistics management in e-commerce. During the process of logistics management development, as government sectors do not pay enough attention to e-commerce logistics, fail to realize the importance for social development, Chinese e-commerce logistics management work is scattered without a well-established laws and regulations for overall restrain, planning and coordination so that the working efficiency of logistics management in e-commerce is low and hard to promote the long-term development of Chinese e-commerce logistics management.

Thirdly, logistics management in e-commerce lack advanced informatization model. Logistics management enterprises have formed good scale in e-commerce. But few can satisfy modernized e-commerce especially during the period of logistics enterprise development. They have not formulated completed informatization model, hard to actively use advanced information technology, mainly reflected as single logistics transportation management model, low efficiency in warehouse transportation and distribution, failure of improving the application quality of information technology, 
failure of realizing automation management, trans-department and trans-industry integration, so that the working quality of logistics management work in e-commerce is low.

Fourthly, logistics management sectors in e-commerce cannot improve logistics distribution efficiency in actual development. Most logistics enterprise provide only warehouse and transportation rather than comprehensive service making the logistics distribution service quality very low, which is also the direct reason to cause low logistics distribution efficiency in Chinese e-commerce. Meanwhile, the transportation method of logistics management in Chinese is simple with no unified standard for transportation equipment which has increased the working procedures of logistics distribution and there are phenomenon of invalid operation so as to reduce the logistics distribution efficiency and increase logistics distribution working cost, making it hard to improve its development efficiency and quality.

Fifthly, e-commerce logistics management lack talent team with high professional quality. It is hard to improve its development efficiency and may cause some problems hard to solve. When hiring talents, relevant management staff do not have strict requirement for the recruitment standard which is hard to improve the recruitment efficiency. After hiring working staff, related management staff cannot conduct stage training for professional knowledge making working staff hard to obtain skills or optimize the logistics management working quality and even cause some problems hard to solve.

\section{Compartment analysis on e-commerce logistics management and traditional logistics management}

E-commerce logistics management refers to using e-commerce network as the operating platform by using modern computer technology to promote logistics enterprise's production and marketing and guarantee optimized management. In e-commerce logistics management, it is necessary to separate people with materials, and use network to carry out related transactions so as to effectively save working time. Below conclusions are obtained after analyzing and comparing e-commerce logistics management with traditional logistics management:

Firstly, the service objects are different. The service object in traditional logistics management is fixed with no big change within short time so as to effectively master customers' demands and formulate completed logistics management system according to customer type to a certain degree. However, e-commerce logistics enterprise' service object has few information knowability and few analysis on customers' demands so as to cause instability to some extent.

Secondly, the creator's values are different. Traditional logistics management sets promotion as the basis of operation so as not to effectively create higher value. But e-commerce logistics management can carry out paid labor service based on the practical condition of market and other economic subjects to ensure providing valuable service for consumers, which also reflects the value of e-commerce logistics management creators.

Thirdly, the commodity information service degrees are different. Traditional logistics management work is to distribute and receive commodities unable to summarize or feedback the commodity information so that consumers cannot find out the practical condition of commodities and there will be information lagging. But in e-commerce logistics, advanced logistics technologies are applied mainly relying on computer technology to carry out service work so as to timely provide feedback of commodity information to consumers and they can comprehensively know commercial information through computer system. E-commerce technology can help consumers track and check commodity information and improve logistics service level.

Fourthly, the calculation methods of the inventory orders are different. In traditional logistics management, inventory will be separately calculated with orders. When calculating the inventory, it is in single direction equal to orders. But in e-commerce logistics management, related technical staff can comprehensively analyze transaction inventory based on the communication between sellers and buyers, so as to effectively improve the development efficiency when adjusting inventory and orders with no fixed and consistent calculation which is influencing the development of e-commerce logistics management to a certain degree. 


\section{Analysis on the importance of e-commerce logistics management model}

E-commerce modernized logistics management enterprises are developing under the promotion of flourishing technologies, and formed good developmental tendency, which has promoted the integration between e-commerce and logistics management and brought about cooperation between two industries for mutual benefit and reciprocity, reflected as below:

\section{Types of e-commerce logistics management work}

The large number of e-commerce logistics management can be divided into below based on the practical development situation of Chinese e-commerce logistics management:

Firstly, e-commerce logistics self-building management system. It means that e-commerce enterprises break through modernized logistics management work, improve resource utilization efficiency and improve e-commerce logistics management competitiveness based on the practical condition of market competition so as to increase the development effect of Chinses e-commerce logistics management enterprise.

Secondly, the third party logistics distribution model. It mainly refers to the cooperation between e-commerce enterprises and related logistics enterprises to make sure the e-commerce products can be sent to consumers and ensure the distribution efficiency and achieve the expecting developmental objective.

Thirdly, the fourth party logistics association mode. It is a brand new concept combining modernized management concept to form completed supply chain integrator so as to effectively improve resource integration utilization efficiency and increase logistics management working effect and achieve the anticipating development objective.

\section{Importance of e-commerce logistics management}

There are huge differences between e-commerce logistics management and traditional logistics management. E-commerce logistics management can change people's life style and concept, improve logistics management working efficiency and optimize logistics management working system.

Firstly, e-commerce logistics management can save working time, improve transaction working efficiency mainly because the network shopping can save consumers' time and further optimize consumers' shopping activities after applying logistics management. After reaching mutual agreement, consumers will place orders and submit to e-commerce logistics to achieve one-stop shopping experience, which can improve consumers' convenience and strengthen sellers' marketing effect and optimizing their working mode ${ }^{[1]}$.

Secondly, in the process of e-commerce logistics practical development. Effective information can form by computer network technology tacking commodity logistics information. After searching and uploading, seller and buyer can observe the commodity logistics information at any time, compare with traditional logistics management methods, and find that it has great advantages which can promote the long-term development of e-commerce logistics management work.

Thirdly, e-commerce logistics management can shorten the distance between people, strengthen interpersonal communication mainly because people in the country can communicate and exchange through network technology after applying e-commerce logistics management technology so that consumers in different areas can comprehensively see and buy commodities and transport through e-commerce logistics management technology and guarantee to satisfy modernized consumers' real demands ${ }^{[2]}$.

\section{Key innovative measures of logistics management in e-commerce}

In the process of innovating e-commerce logistics management technology, related management staff should analyze Chinese e-commerce development tendency to satisfy people's demand for e-commerce logistics management and timely solve various problems, and innovate logistics management work so as to promote the long-term development of e-commerce logistics management work. Specific innovative measures include below aspects: 


\section{Realize zero inventory}

In the process of innovating e-commerce logistics management, commodity manufacturers and supplier can realize zero inventory management and improve capital application efficiency. For consumers, it is necessary to provide cheap and fine products, improve logistics transportation speed and satisfy consumers' real demands. Therefore, in the process of management, it is urgent to achieve the purpose of zero inventory and improve cargo distribution efficiency, quicken the speed of cargo circulation so as to achieve the purpose of seller and consumer win-win ${ }^{[3]}$.

\section{Formulate direct transfer strategic scheme}

In modern logistics enterprise's development, related management staff must make cross-functional and cross-enterprise treatment and formulate multi-parity cooperative logistics management strategic model which can save enterprises' working time and reduce various capital problem, speed up logistics and improve logistics service quality to satisfy consumers' demand.

\section{Perfect laws and regulations on e-commerce logistics management}

E-commerce logistics management laws and regulations should be further improved so as to improve the e-commerce logistics management working efficiency and use completed laws and regulations to standardize their behaviors, which requires for government sectors to formulate solid law and regulations based on the development situation of e-commerce logistics management and reduce problems and help related organizations to improve logistics management work quality ${ }^{[4]}$.

\section{Strengthen the construction of informatization system}

E-commerce logistics management staff should actively construct informatization system and improve the logistics management enterprises' efficiency. Firstly, they should use information technology to improve logistics distribution methods to guarantee speeding up distribution speed and reduce the problems existing in distribution. Secondly, pay attention to the optimization of modernized logistics distribution process and satisfy consumers' demands for distribution process and improve distribution working quality.

\section{Innovate e-commerce logistics management skills}

During applying e-commerce logistics management technologies, related technical staffs should make effective innovation to promote the intelligent development of logistics operation model. Firstly, technical staffs must increase the investment into logistics infrastructure and introduce advanced management technologies and actively apply modernized logistics management technologies. Secondly, e-commerce logistics management staff need to innovate logistics management technologies in different stages and formulate completed intelligent logistics management technologies and perfect logistics intelligent management technology system to promote its long-term progress [5].

\section{Establish high-quality talent team}

E-commerce logistics management enterprises need to build modernized high-quality talent team and hire talents with high professional qualities with working experience to improve logistics management efficiency. Meanwhile, e-commerce logistics enterprises should provide professional training for employees in different stages so that they can acquire advanced electronic logistics management skills and increase e-commerce logistics management enterprises' core competitiveness.

\section{Conclusion}

The development of Chinese e-commerce logistics management technology requires for management staff and technical staff to formulate completed management system and gradually innovate e-commerce logistics management method, establish high-quality talent team and create new chances for the development e-commerce logistics management enterprise.

\section{Acknowledgement}

This paper is the project of Henan provincial social science circle federation, title "Studies on fresh agricultural product circulation model in Henan province in the age of Internet +", No.: SKL-2016 -3344 


\section{Reference}

[1] Zeng Xuewen. Exploration of the relation between logistics management and e-commerce, Dual Use Technologies \& Products, 2015(20):50-50.

[2] Liu Yingshan, Sun Yan. Exploration of the innovation of logistics management in e-commerce, Journal of Chifeng University (Natural science version), 2015(5):71-73.

[3] Liu Shujuan. Analysis on logistics management and e-commerce,Market Modernization, 2016(4):45-45.

[4] Wang Xinqiao. Analysis on the relation between logistics management and e-commerce, Modern Business, 2012(10):61-61.

[5] Chen Shuang. Innovation of logistics management in e-commerce environment, Logistics Engineering and Management, 2016,38(4):49-50. 